\title{
Modifications of Engineering Management Program at California State Uni- versity Northridge
}

\author{
Alireza Kabirian, California State University Northridge
}

Alireza Kabirian is currently an assistant professor of Engineering management at California State University Northridge. He obtained a Ph.D. in Industrial Engineering from Iowa State University in 2009. After graduation, he taught in the Business School of the University of Alaska Anchorage for two years before leaving the Last Frontier to join CSUN. His research areas are focused on Operations Research, Applied Statistics, and Engineering Education.

\section{Dr. S. Jimmy Gandhi, California State University, Northridge}

Dr. S. Jimmy Gandhi is currently an assistant professor in the Manufacturing Systems Engineering \& Management (MSEM) Department at California State University, Northridge. He teaches courses in quality management, entrepreneurship and systems engineering. Prior to coming to Cal State, he was with the School of Systems and Enterprises at Stevens Institute of Technology and also taught at the Zicklin School of Business at Baruch College, which is part of the City University of New York (CUNY). Dr. Gandhi has research interests in the fields of globalization, risk management and sustainability. He is an active member of ASEM, ASEE and participates in their conferences on a yearly basis. He has a PhD in Engineering Management from Stevens Institute of Technology, a M.S. in Engineering Management from California State University, Northridge and a B.S. in Engineering from Illinois Institute of Technology.

\section{Dr. Ileana Costea, California State University, Northridge}

Ileana Costea is currently Professor of Automation Engineering and Chair of the Manufacturing Systems Engineering Department, College of Engineering and Computer Science, California State University, Northridge (CSUN). Ileana has a Ph.D., in Decision Analysis/Operations Research from the University of California, Los Angeles (UCLA). She has done undergraduate instruction in Manufacturing Systems Engineering and Engineering Management and graduate instruction in Manufacturing Systems Engineering. Professionally active internationally, including Visiting Professor appointments at several universities in Europe and membership on organizing committees for international conferences. Researched and published extensively on artificial intelligence, interactive computer graphics, and other areas associated with $\mathrm{CAD} / \mathrm{CAM} / \mathrm{CAE}$, and recipient of the Engineer's Council Merit Award for work in these areas. She was a reviewer for NSF and IEEE and editor of several special journal issues. She has been actively involved with the WESTEC manufacturing Trade Show and Conference of the Society of Manufacturing Engineers (SME). She has organized numerous technical sessions and session tracks at various national and international events, and has been a judge several years for the Manufacturing Challenge student competition of SME. Ileana is a member of ASEE, ASQ and SME.

\section{Dr. Ahmad R Sarfaraz, California State University, Northridge}

Dr. Ahmad Sarfaraz gives undergraduates instruction in Manufacturing Systems Engineering and graduates instruction in Engineering Management. Dr. Sarfaraz's current research focuses on operations research and operations management, AHP and FAHP applications, and economic analysis. Dr. Sarfaraz is the author and co-author of numerous publications in international journals including international journal of production research and journal of engineering design. Extensive industry experience and consulting, Recipient of Engineer's Council Merit Award for the year 2002. Director of MSEM Solutions Center and Facilities-VEDC community service learning.

Dr. Mark Rajai, CSUN 


\title{
An innovative approach to an online program for Engineering Management at CSUN
}

\begin{abstract}
This paper discusses the structure, requirements, and teaching methods of a new Online Master of Science degree in Engineering Management (EMOL) to be offered through Tseng College, an extended learning wing of California State University-Northridge (CSUN). This new program is significantly different from the residential program currently offered by Manufacturing Systems Engineering and Management (MSEM) department of CSUN in a number of aspects. To come up with our ideas for restructuring the Engineering Management (EM) program, we first conducted a benchmarking effort, by reviewing various EM programs. In this paper, the authors have summarized the results of their research about similar programs offered in leading US schools. The authors are in the processes of implementing two categories of changes: first restructuring program requirements and then modernizing the teaching and delivery methods. These two together should modernize the statuesque to bring it to the state of the art education of EM.
\end{abstract}

\section{Benchmarking}

There are many schools around the country that offer similar degrees to The Master of Science (MSc) in EM, some are residential programs and a few are online. We did a research comprising about 10 leading colleges around the country and looked into their program structures, requirements and strategies. These schools are Johns Hopkins University, Massachusetts Institute of Technology, Cornell University, Case Western Reserve University, Drexel University, Duke University, Dartmouth University, Northwestern University, University of California-Irvine, and Purdue University. This was done because the authors thought it was worthwhile looking at what others are doing before they made any significant changes to the program at CSUN. In the following, the authors have summarized their observations about 5 of these schools; the other five are similar.

- Purdue University [1] offers an online Master of Engineering with concentration in Engineering Management and Leadership. The program consists of 33 credit hours and is a joint collaboration between the engineering and business schools though it is administered by engineering school. The engineering courses are offered by the Purdue College of Engineering and the students are embedded in classes composed of engineers who are seeking various engineering graduate degrees. The business courses of the program are taught by the Thunderbird School of Global Management at Purdue and the students are embedded in classes composed of those seeking Master of Business Administration (MBA). The coursework requirements cover almost all the topics offered in CSUN's residential EM plus a very wide set of additional courses in business, industrial engineering, and manufacturing. Among the courses that the authors did not expect to see are Global Political Economy, Global Negotiations and Globalization and Engineering. The program seems to be an integration of a traditional Industrial Engineering (IE) and MBA, is very modern and globalization-flavored. 
- The University of California-Irvine [2] has an MSc program in EM which is jointly offered by The Paul Merage School of Business and The Henry Samueli School of Engineering. The program flyer says the major "teaches business from the engineering perspective and engineering from the business perspective and students will learn to think about their work through the lens of innovation and to develop a crucial view to enhance their careers." The MSc degree requires the completion of a minimum of 17 courses (minimum of 45 units) beyond the bachelor's degree. As part of the program, students must complete a two-week orientation and an intensive course in early to mid-September preceding the Fall Quarter. The major requirements are somewhere between IE and MBA. A feature of this program is that it requires the students to take engineering courses in their primary specializations: Biomedical Engineering, Biochemical Engineering, Electrical and Computer Engineering, Materials Science Engineering, Civil Engineering, or Mechanical and Aerospace Engineering.

- Northwestern University [3] has a Master of EM (MEM) which is administered by the department of Industrial Engineering and Management Sciences. The program flyer says "MEM degree offers the practical business perspective needed by technical managers. Unlike a traditional MBA program, the MEM Program emphasizes skills specifically required in technology-based organizations." But when the authors researched the program, it has 6 core courses that are pretty much the typical requirements of an MBA, though they somehow accommodate engineering titles:

$\circ$ Engineering Management (gateway course)

$\circ$ Accounting for Engineers

- Financial Issues for Engineers

$\circ$ Marketing Issues for Engineers

- Decision Tools for Managers

- Strategic Management for Engineers (capstone course)

The students should take the above 6 cores and 6 others as electives; of which some are taught in business school. The program allows optional concentrations in one of 3 areas: Supply Chain and Operations Management, Design \& Innovation, or Project and Process Management.

- Dartmouth University [4] also has a Master of EM (MEM) that is "jointly taught by faculty from Thayer School of Engineering and Tuck School of Business." The program consists of 14 courses; of which eight are required and the rest are electives. The cores are:

- Applied Mathematics (2 courses)

- Statistical Methods in Engineering

- Introduction to Optimization Methods

- Engineering Project/Design Sequence (2 courses)

- Technology Assessment

- M.E.M. Project/Internship

$\circ$ Engineering and Engineering Management Required Courses (6 courses)

- Decision-Making Under Risk and Uncertainty

- Financial and Managerial Accounting

- Corporate Finance

- $\quad$ Marketing

- Operations Management 


\section{- $\quad$ M.E.M. Professional Skills}

This program seems to be heavily quantitative and again combines MBA and IE apparently.

- Duke University [5] has a Master of EM. The requirements are 4 core management courses, 4 technical electives, an internship, and 2 semesters of Seminar and Workshop Series. The core includes:

○ Marketing

○ Intellectual Property, Business Law, and Entrepreneurship

$\circ$ Finance and Accounting for Technology-Based Companies

$\circ$ Management in High-Tech Industries

The degree can be customized through 2 concentrations: 1) Management of Technology Concentrations (a number of MBA courses) and 2) Science and Technology (a variety of courses from different engineering disciplines such as Biomaterials, Energy and Environment, Photonics, etc.). In fact the program starts out with learning what management means, then the students are split into two tracks, those who want to know more about management and business and others who want to go back to refresh their engineering background. A major attraction of this program is heavy emphasis on a series of lectures through Seminars and Workshops after meeting coursework requirements. In fact the program invites prominent industry leaders, experienced business managers, entrepreneurs, venture capitalists, and small-business owners to guestlecture. A weekly post-seminar reception allows students to talk one-on-one with speakers and network with their peers and this reportedly has helped in job placement of graduates.

\section{Proposed Structural Changes to EMOL}

CSUN is currently offering a residential program of EM and is in the process of restructuring its EMOL program. The EMOL program existed at CSUN; but it was stopped due to administrative issues. We are now in the process of revamping the program. We proposed restructuring the requirements of EM OL to distance the program from IE. Our residential program looks very similar to a typical IE program. In this section, we lay out the changes in the structure of our programs that are under implementation.

\subsection{Program Requirements}

The new EMOL program will center around two certificates, namely Entrepreneurship \& Innovation Management and Production \& Supply Chain Management. Each certificate will have 5 courses. Details are as follows:

Certificate \# 1 - Entrepreneurship \& Innovation Management (15 credits, 5 courses at 3 credits each)

- Leadership in high tech firms in the 21 st century

- Strategic Management \& Marketing for Engineers

- Engineering Economy and Financial Analysis

- Entrepreneurship \& Engineering Innovation Management 
- Sustainability for Engineers

Certificate \# 2 - Production \& Supply Chain Management (15 credits, 5 courses at 3 credits each)

- Decision Tools for Engineers

- Project Management for Engineers

- Production \& Operations Management

- Total Quality Management

- Global Supply Chain Management for Engineers

We also defined a Capstone Project course ( 3 credits) as culminating experience.

The structure of this online program is such that the students have the flexibility to take either one certificate and graduate with one certificate. Alternatively, the students can also continue to work on their master's degrees after they complete their first certificate. In order to get their master's degree, they have to take another 5 courses and then also work on a capstone project (3 credits).

In addition to the structure of the online program, the courses offered as part of this online program are unique as compared to other online EM programs in the following ways.

The course titled, "Entrepreneurship \& Engineering Innovation Management," will be created to cater to students in the online program and will teach students to use all the latest tools online to create their business plan, thus making it relevant of the 21 st century.

The course titled "Strategic Management \& Global Marketing for Engineers" is a course offering a unique combination of skills that need to be taught to engineering managers and will offered to students through this course.

The Sustainability for Engineers course is also unique in this program. Currently there are no courses being offered in EM programs as far as we know to help the managers understand sustainability issues, particularly related to the global supply chain. This is an imperative topic for managers to understand as $90 \%$ of the world's emissions and footprints (Carbon, Water, etc) are created in the global supply chain.

The course titled "Decision Tools for Engineers" will offer a set of tools for engineering managers, including statistics, simulation and modeling as well as topics in operations research.

\subsection{Timeline of the Program}

The new program can be completed in 2 years. We breakdown each year into 3 semesters, each of which lasts 3.5 months with a two-week break in between. Here's the time breakdown:

- Fall Semester: September to mid-December

- Christmas Break: 2 weeks in the second half of December

- Spring Semester: January to mid-April 
- Spring Break: 2-weeks in the second half of April

- Summer Semester: May to mid-August

- Fall Break: 2-weeks in the second half of August

The program will be launched in Fall 2014. In the first year, we only will have first-year students. Starting in the academic year 2015-2016 onward, we will have both freshmen and continuing students and will need to offer enough courses for both groups. Therefore, we anticipate offering 2 courses per certificate in the first two semesters of each academic year and one per certificate plus the culminating experience in the third semester. The following table shows a typical schedule for the courses offered in academic year 2014-2015:

\begin{tabular}{ll}
\hline Fall 2014 & - Leadership in high tech firms in the 21st century \\
& - Strategic Management \& Marketing for Engineers \\
& - Pecision Tools for Engineers \\
\hline Spring 2015 & - Engineering Economy and Financial Analysis \\
& - Entrepreneurship \& Engineering Innovation \\
& - Management \\
& - Production \& Operations Management \\
Summer 2015 & - Total Quality Management \\
& - Sustainability for Engineers \\
& - Culminating Experience \\
\hline
\end{tabular}

\section{Proposed Teaching and Delivery Methods}

\subsection{Restructuring}

The authors' suggestion for the EMOL program is to develop a fully online project-based learning environment. This development requires collaboration between professors to design the courses differently, alumni and industry experts to provide data about relevant projects, computer programmers to design an interactive online environment, IT experts to facilitate live or recorded communications and the administrations and staffs of both our College of Engineering and Computer Science (CECS) and Tseng College to support and market the program, and handle student affairs.

\subsubsection{Project-Based Course Break-Down}

In this new learning-centered approach, professors will not teach from a text book chapter by chapter or assign students to do end-of-chapter problems as homework. This is the traditional method that only teaches formulae, abstract concepts, and how to solve clear-cut problems. Instead, with this new proposed methodology each course will be split into several relevant projects (between 5 to10 per course). Each project will cover the materials that were supposed to be taught in 1-2 chapters of the traditional textbook of the course and even some concepts from prior courses have taken in a sequence. This will link courses among each other and offer an 
integrated program in EM. Thus, if a student takes Decision Tools for Engineers first and then Engineering Economy and Financial Analysis, the Engineering Economy and Financial Analysis projects will be defined in a way which draws upon new knowledge gained in Engineering Economy and Financial Analysis and maybe some stochastic parts that require recalling and applying the concepts learnt in Decision Tools for Engineers. This teaching paradigm starts out by understanding the problem(s) at hand in each project. Then the professor will teach some new techniques and concepts relevant to the project, and the students will work on the project as a team with the assistance of the instructor. Any theory or new concept that the student must learn will be grasped while working on a real application. This will motivate the students to learn concepts whose relevance to their work in industry they will see, and will enhance their confidence about applicability of the materials, teach them how to work with others and think outside the box in each course, as well as improve their communication and presentation skills, preparing them better for becoming problem solvers/decision makers in the work space.

\subsubsection{Project Portal Development}

Computer programmers will be needed in the development process to work with the professors to create an online environment called Project Portal. Each project is uploaded on the online framework in an organized way. For instance, a case study regarding a manufacturing company $\mathrm{ABC}$ used in Engineering Economy and Financial Analysis course can have a tab for each organizational department of the production facility at ABC (marketing, accounting, human resources, management and operations) which contains the data and documents provided by the department. The students could switch between tabs to read the documents, e-mails, and information exchanges, and try to look at the problem from different angles and the perspectives of various organizational departments. The environment also should have analysis tools and sections that asked the students to provide their assumptions, answer some key questions and write a report containing their analysis of the problem, and upload any supporting file they used to analyze the problem. Several other features will be included in Project Portal to make it attractive and facilitate communication among the team members and between students and the instructor.

\subsubsection{Obtaining Projects}

Good, relevant, actual industry projects are needed for each course in the EM program. The way to find them would be to by contacting CSUN alumni, using student projects/theses in previous cohorts if we define thesis requirement, talking to the Industry Liaison Council at CSUN, or other industry experts to see if they have any relevant projects they can provide us with. This might even open a consulting or grant-seeking opportunity for the faculty to first solve the industry/business problem and then transfer the material to one of the courses with prior agreement with the industry. The project providers from industry will also be invited to guestlecture and talk about their specific industry and/or the project for the students. After we let the students attempt to work on the project and turn in the results, we can ask the industry link who provided the project to come talk again about their way of analyzing the project and consequences of implementing the outcomes of their analysis. Of course, the last resource that professors will use as projects is case-study textbooks since they are widely available for each topic. Or the teachers can collect projects/cases from different textbooks. This is feasible today, 
given the e-publishers making possible the creating of a specific textbook where an instructor can combine chapters and papers from various sources.

\subsubsection{Delivery and Communication Methods}

Several delivery methods and communication tools are anticipated to be used together for this online education system. The core idea is to make the courses project-based and the Project Portal development is the major structure to be developed. We will use Moodle and other tools already available at CSUN to communicate with the students, upload off-line video and audio files and course materials, and run live video/conference calls. An IT studio (class)room in CSUN is also equipped with all state-of the art video and audio recording and broadcasting tools. The faculty are trained with the tools and assisted by IT experts throughout the program.

\subsubsection{Guest Speakers and Seminar Course}

The idea that no faculty may know everything a student should learn makes us believe that outside speakers can sometimes be used as part of the education system proposed. We anticipate using guess speakers in different parts of the online education system.

The speakers may be providers of the course projects and case studies. Section 2.3 explains about what these speakers are asked to lecture on.

Some graduate students of MSEM department have recently established a student group at CSUN named Engineering Management Student Association (EMSA). One of the future activities of the EMSA is to invite people from industry to guest lecture on their work experience for residential students. We intend to record all these lectures and distribute and integrate them as part of course delivery system for EMOL.

\subsubsection{Quality Improvement}

This restructuring proposal will not be a one-time improvement effort. Instead, a continuous improvement process is implemented for the program by creating a feedback loop between stakeholders of the program (students, faculty, administration, alumni, and industry) and periodic revision of the structure after its launch. The contacts with alumni and industry experts to get projects should also help us build part of the feedback loop. Not only are we inquiring these groups for new projects and implement them in our courses, but also we ask them about the current trends in industry, hot topics of interest, new skills necessary for our students, and jobhunting tips. This information will be incorporated in cohort-by-cohort and semester-by-semester revisions of the program. Indeed, this continuous quality-improvement should lead us in targeting an innovative and outstanding online program over time.

\section{Conclusion:}

In conclusion, the authors think the titles of the core courses of EM and MBA are not very different; even the underlying theories taught are pretty much the same. What distinguish the two programs are applications, perspectives, and some elective courses. EM uses technology 
examples to teach finance for instance, MBA uses investments in bonds and stocks to teach the same. It seems that Engineering and Business deans of the universities we researched about have come to this kind of agreement and understanding about the similarities and differences of EM and MBA. The business schools have even allowed the EM students to sit with their MBA students in some business classes. The authors have organized the restructuring of the new EMOL program around these observations.

The key advantages of this development and restructuring process are as follows:

- Making an extraordinary online program, in high demand, flexible and current

- Allowing the creation of material specific to the cohort and the industry in represents

- Switching from teaching by lecturing, to learning by applying

- Emphasizing problem solving, critical thinking, and decision making

- Softening the borders between different courses or even majors by defining multidisciplinary projects that, although have target lessons, they draw on various skills/knowledge

- Creating a solid network with industry people (local as well as national or even international) and alumni

- Offering projects to students and faculty which can result in publications

- Opening consulting possibilities for faculty

- Modernizing the residential EM program by using elements developed for the online program

- Lastly, the authors would like to emphasize that creating a new program is an iterative effort and it is crucial to be agile and be able to make changes to the program in correspondence with changing industry needs, in a timely fashion.

\section{References}

[1] https://engineering.purdue.edu/ProEd/credit/eml

[2] http://www.eng.uci.edu/grad/programs/em

[3] http://www.mem.northwestern.edu/

[4] http://engineering.dartmouth.edu/academics/graduate/mem/

[5] http://memp.pratt.duke.edu/ 